\title{
Michel de L'Hospital, Carmina. Livre I
}

\section{Dario Cecchetti}

\section{OpenEdition}

\section{Journals}

\section{Edizione digitale}

URL: http://journals.openedition.org/studifrancesi/397

DOI: 10.4000/studifrancesi.397

ISSN: 2421-5856

\section{Editore}

Rosenberg \& Sellier

\section{Edizione cartacea}

Data di pubblicazione: 1 aprile 2015

Paginazione: 135

ISSN: 0039-2944

\section{Notizia bibliografica digitale}

Dario Cecchetti, « Michel de L'Hospital, Carmina. Livre I », Studi Francesi [Online], 175 (LIX | I) | 2015,

online dal 01 avril 2015, consultato il 18 septembre 2020. URL : http://journals.openedition.org/ studifrancesi/397 ; DOI : https://doi.org/10.4000/studifrancesi.397

\section{Questo documento è stato generato automaticamente il 18 settembre 2020.}

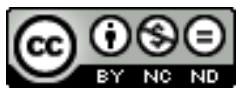

Studi Francesi è distribuita con Licenza Creative Commons Attribuzione - Non commerciale - Non opere derivate 4.0 Internazionale. 


\title{
Michel de L'Hospital, Carmina. Livre I
}

\author{
Dario Cecchetti
}

\section{NOTIZIA}

MICHEL DE L'HoSPITAL, Carmina. Livre I, édité, traduit et commenté par Perrine GALAND et Loris PETRIS, avec la participation de David AMHERDT, Genève, Droz, 2014 («Travaux d'Humanisme et Renaissance», n. DXXXI), pp. 398.

1 Nel quadro di un rinato interesse per la poesia neolatina del Cinquecento francese si sono negli ultimi decenni moltiplicate le edizioni di testi (possiamo citare la pubblicazione dei poemata di Du Bellay, Jean Second, Jean Salmon Macrin, Étienne Dolet, Jean Dorat, ecc.), che ricordano come questa produzione neolatina accanto all'affermarsi del volgare «dimostri il perdurare di una forte tradizione in latino della poetica érasmisante a fianco dell'illustration della lingua francese, che continua ad essere inquadrata e influenzata dal permanere di questa stessa tradizione latina». È ora benvenuta l'edizione critica dei Carmina di Michel de L'Hospital di cui esce il primo libro.

2 L'Hospital è ricordato soprattutto sul piano della storia civile come esponente, nel momento in cui hanno inizio in Francia le guerre di religione, di una politica di pacificazione, quasi precursore dell'idea di tolleranza (peraltro secondo una mitizzazione del personaggio a volte fuorviante). In realtà ha una doppia appartenenza, al mondo del Diritto e al mondo delle Lettere, per la sua attività di magistrato e per la sua formazione umanistica, debitrice delle idee di Erasmo e Budé sulla conciliazione tra esercizio della politica e pratica letteraria. Ottenne d'altronde una fama notevole proprio per i suoi Carmina (Epistolae seu Sermones) che si apparentavano, nel momento in cui trionfava il genere dell'ode oraziana, al genere (anch'esso oraziano) dell'epistola metrica e del sermo. I carmina di L'Hospital offrono anzitutto una riflessione sull'ispirazione poetica che si riallaccia alle nuove definizioni che Poliziano, sulla scorta di Quintiliano e di Stazio, aveva dato della natura del poeta: il furor divino descritto da Platone era sostituito dal calor, slancio affettivo sostenuto da una profonda erudizione, 
più adatto alle effusioni intime che all'epopea o alla tragedia; più adatto anche all'espressione dei sentimenti e dei pensieri dell'uomo politico, immerso negli impegni della quotidianità. Il libro I, come saranno anche i libri successivi, è una testimonianza interessante della spiritualità sia dei letterati usciti dall'Umanesimo erasmiano sia di una classe sociale formata da politici e giuristi impegnati nel servizio dello stato. Si tratta di una spiritualità impregnata di evangelismo e di stoicismo. Infatti, da un lato abbiamo considerazioni sul ruolo che la vita spirituale e la fede hanno - al di là di qualsiasi disquisizione di teologia dogmatica - al centro dell'esistenza (I, 11), come pure considerazioni sul senso spirituale della malattia (I, 6) e della morte (I, 9); dall'altro, vediamo tratteggiato il profilo del magistrato integro e inaccessibile ai vizi quasi fosse il modello del saggio stoico (I, 2). Ancora, L'Hospital definisce (I, 7) cosa può intendersi per poesia cristiana, spoglia dell'ornatus pagano e incentrata su una semplicità che traduce la sincerità.

3 L'edizione critica è veramente esemplare, basata sul testo autografo del manoscritto Dupuy, quando esiste; sul testo delle plaquettes edite quando L'Hospital era in vita, se ce ne sono; in mancanza di questi testi, su quello dell'edizione del 1732. Oltre ad avere una nitida traduzione a fronte (cosa utile, data la difficoltà a volte del latino umanistico), ciascun carmen è accompagnato da un'analisi che lo inquadra nel contesto culturale, illustrandone gli orientamenti spirituali, filosofici e politici, la struttura retorica, i giochi intertestuali; inoltre un "Commentaire», ricco di annotazioni minuziose, evidenzia fonti ed enuclea tematiche. Si segnala, infine, l'accuratissimo «Index des matières» utile per reperire gli argomenti trattati (in funzione del riferimento con la produzione coeva). 